\title{
Produtividade, anatomia foliar e qualidade de frutos de híbridos de tomateiro tipo Saladete sob ambiente protegido
}

Produzir tomates na Amazônia é um desafio, devido às altas temperaturas e precipitação. O objetivo deste estudo foi identificar o híbrido de tomateiro com maior desempenho produtivo e qualidade de fruto sob cultivo protegido em condições de altas temperaturas. O cultivo foi realizado em sistema tutorado em meia estaca, sem podas, sob cultivo protegido do tipo arco, em Nova Mutum - MT. O delineamento experimental adotado foi de blocos ao acaso, com cinco repetições. Foram aferidos parâmetros produtivos, físico-químicos, bioquímicos de frutos e a anatomia foliar. O híbrido 'Lampião' 'Fascínio', 'Vedette' e 'Shanty' se destacaram em produção e qualidade nutricional, comparado aos demais. Os parâmetros da anatomia foliar analisados demonstraram alterações adaptativas à luminosidade difusa, umidade e temperatura, não demonstrando correlação com a produção dos híbridos avaliados. Quanto a coloração do fruto, o híbrido 'Candieiro' apresentando coloração mais vermelha. O híbrido 'Mariana' mostrou menor desempenho em produtividade, altura da planta e concentração de licopeno, demonstrando menor adaptação ao ambiente protegido sob altas temperaturas.

Palavras-chave: Solanum lycopersicum L.; Adaptação; Estômatos; Horticultura tropical; Cultivo protegido.

\section{Productivity, leaf anatomy and fruit quality of tomato salad hybrid hybrids under protected environment}

\begin{abstract}
Producing tomatoes in the Amazon is a challenge, due to high temperatures and precipitation. The objective of this study was to identify the tomato hybrid with the highest productive performance and quality of fruit under protected cultivation under high temperature conditions. The cultivation was carried out in a tutored system in half stake, without pruning, under protected cultivation of the arch type, in Nova Mutum - MT. The experimental design adopted was randomized blocks, with five replications. Productive, physical-chemical, biochemical fruit parameters and leaf anatomy were measured. The hybrid 'Lampião' 'Fascínio', 'Vedette' and 'Shanty' stood out in production and nutritional quality, compared to the others. The leaf anatomy parameters analyzed showed adaptive changes to diffuse light, humidity and temperature, showing no correlation with the production of the evaluated hybrids. As for the color of the fruit, the hybrid 'Candieiro' showing more red color. The hybrid 'Mariana' showed lower performance in productivity, plant height and lycopene concentration, showing less adaptation to the protected environment under high temperatures.
\end{abstract}

Keywords: Solanum lycopersicum L.; Adaptation; Stomata; Tropical horticulture; Protected cultivation.

Simone Aparecida Domiciano (D) Universidade do Estado de Mato Grosso, Brasil http://lattes.cnpq.br/8200835060937720 http://orcid.org/0000-0002-3180-5640 sidomicianoaf@hotmail.com

\section{Jéssica Gawski Casagrande (iD)}

Universidade do Estado de Mato Grosso, Brasil http://lattes.cnpq.br/0754361440961615 http://orcid.org/0000-0002-5673-7111 jessicacasagrande2006@hotmail.com

\section{Rejeane Maria da Silva (10)}

Universidade do Estado de Mato Grosso, Brasil http://lattes.cnpq.br/5769219388344076 http://orcid.org/0000-0001-7211-3213 rejeane maria@hotmail.com

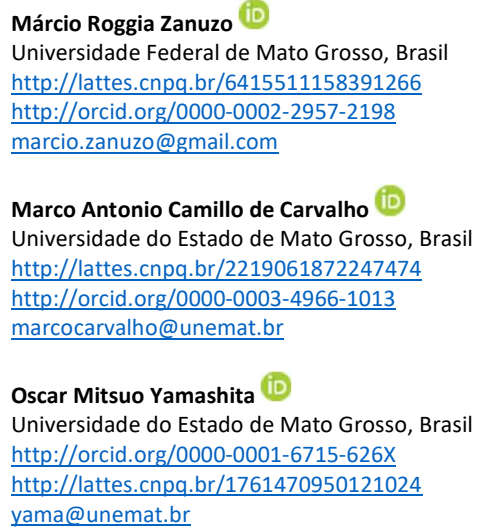

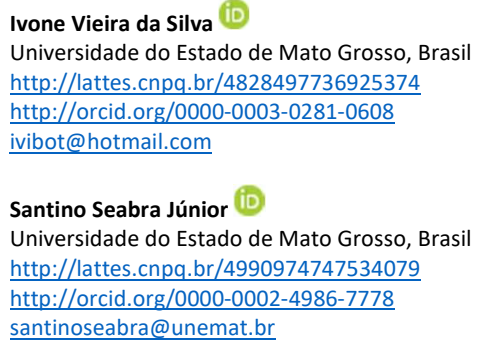

Referencing this:

DOMICIANO, S. A.; CASAGRANDE, J. G.; SILVA, R. M.; ZANUZO, M. R.; CARVALHO, M. A. C.; YAMASHITA, O. M.; SILVA, I. V.; SEABRA JÚNIOR, S.. Produtividade, anatomia foliar e qualidade de frutos de híbridos de tomateiro tipo Saladete sob ambiente protegido. Revista Ibero Americana de Ciências Ambientais, v.12, n.2, p.111-124, 2021. DOI: http://doi.org/10.6008/CBPC2179-6858.2021.002.0012 


\section{INTRODUÇÃO}

Tomates (Solanum lycopersicum L.) são consumidos e cultivados em praticamente em todo o mundo, e em 2018, a produção mundial de tomate foi de 182,256 milhões de toneladas. A produção brasileira no ano de 2017 foi de 4,37 milhões de toneladas, neste cenário, o estado de Mato Grosso produziu, no ano de 2017, 4.761 toneladas de tomate (IBGE, 2018), insuficiente para suprir a demanda Estadual.

O tomate contém baixa concentração de calorias e gorduras, possui açúcares (glicose e frutose), ácidos, carotenoides como a provitamina $\mathrm{A}$ ( $\beta$-caroteno), licopeno, a vitamina $\mathrm{C}$ e traços de potássio, fósforo, ferro, entre outros (PAULA et al., 2015).

A demanda dos tomates do grupo Saladete também conhecidos como italiano tem aumentado no Brasil, além de apresentar alto teor de sólidos solúveis totais, os frutos são indicados tanto para processamento, quanto para consumo in natura (FERNANDES et al., 2018), proporciona frutos alongados, biloculares, polpa espessa e são firmes e saborosos.

A qualidade do tomate pós-colheita se relaciona com o seu ponto de maturação, determinado por alterações fisiológicas, bioquímicas e moleculares, modificando características físico-químicas e compostos bioativos, que também são influenciados pelo genótipo e pelas diversas práticas culturais e aspectos agronômicos (PAULA et al., 2015).

Em ambiente protegido há modificação de radiação, com luz difusa, além de proporcionar controle parcial das condições edafoclimáticas, permitindo a realização de cultivos em épocas consideradas desfavoráveis para a produção a campo (RAMPAZZO et al., 2014). Esta variação de luminosidade pode causar alterações nas respostas fisiológicas, bioquímicas e anatômicas da planta (ARAGÃO et al., 2014). Considerando as características específicas do cultivo do tomateiro, torna-se necessária uma comparação entre diferentes híbridos dentro das mesmas condições edafoclimáticas, avaliando adaptação e qualidade de frutos, possibilitando a identificação do mais apto para a região. Esses estudos têm sido utilizados, para qualificar, avaliar e recomendar novos híbridos.

O cultivo protegido tem contribuído para a eficiência no rendimento agronômico e qualidade do tomate, principalmente no período de entre safra de produção que ocorre na primavera-verão, conferindo melhores preços de comercialização dos frutos (OTONI et al., 2012).

Considerando a demanda de produção em regiões de altas temperaturas e pluviosidade, Schwarz et al. (2015) argumentam que é necessária a avaliação de híbridos dentro das mesmas condições de cultivo, permitindo fazer comparações genéticas, produtivas, de qualidade e conhecer as mais adequadas para esta região, pois cada material tem suas características genéticas que determinam sensibilidade às condições ambientais e a outros fatores de produção. Diante do exposto, o objetivo deste estudo foi identificar o híbrido de tomateiro com maior desempenho produtivo e qualidade de fruto sob cultivo protegido em condições de altas temperaturas. 


\section{MATERIAIS E MÉTODOS}

\section{Condução das plantas}

Os sete híbridos avaliados com crescimento determinado e fruto do tipo Saladete ('Vedette', 'Fascínio' (Feltrin), 'Lampião', 'Candieiro' (Agristar), 'Tytanium' (Agro Cinco), 'Mariana' (Sakata) e 'Shanty' (Hazera)) foram cultivados em sistema convencional em casa de vegetação. O clima é tropical úmido tipo Aw, classificado de acordo com Köppen, com chuvas concentradas no verão (outubro a abril). A precipitação média anual de $1900 \mathrm{~mm}$ e a temperatura média de $26^{\circ} \mathrm{C}$. O solo é classificado como Latossolo VermelhoAmarelo Distrófico.

$\mathrm{Na}$ adubação foi utilizada $8 \mathrm{t} \mathrm{ha} \mathrm{T}^{-1}$ esterco de galinha, $888,9 \mathrm{~kg} \mathrm{ha}^{-1}$ de ureia $(45 \% \mathrm{~N}), 1.333,3 \mathrm{~kg} \mathrm{ha}^{-1}$ de cloreto de potássio $\left(60 \%\right.$ de $\left.\mathrm{K}_{2} \mathrm{O}\right)$ e $2.777,8 \mathrm{~kg} \mathrm{ha}^{-1}$ de superfosfato simples (18\% $\left.\mathrm{P}_{2} \mathrm{O}_{5}\right)$, distribuídos durante o ciclo do tomateiro, utilizando $100 \%$ do esterco e do superfosfato simples, $10 \%$ da ureia 'e do cloreto de potássio incorporados no sulco de plantio, 20 dias antes do transplante. 0 restante do adubo foi distribuído via fertirrigação, sendo parcelado em doze aplicações durante o ciclo da planta, utilizando o sulfato de amônio $\left(20 \% \mathrm{~N}\right.$ ) e nitrato de potássio ( $13 \% \mathrm{~N}$ e $46 \%$ de $\left.\mathrm{K}_{2} \mathrm{O}\right)$.

No período do cultivo, as temperaturas no interior do ambiente protegido a $1 \mathrm{~m}$ de altura foram 22 , 31 e $36^{\circ} \mathrm{C}$, para temperatura mínima, média e máxima, respectivamente.

A semeadura foi realizada em 11 de janeiro de 2018, em bandejas com substrato comercial Vivatto ${ }^{\circledR}$, em ambiente protegido tipo capela com pé direito de $3 \mathrm{~m}$, sendo transplantadas as mudas com 32 dias após a emergência. $O$ ambiente foi protegido coberto com filme agrícola de 150 micras e laterais revestidas com tela de sombreamento preta $50 \%$ e dimensões de $7 \mathrm{~m} \mathrm{X} 21 \mathrm{~m}$. O tomateiro foi conduzido no sistema meia estaca, espaçamento de $1 \mathrm{~m}$ entre linhas e 0,4 entre plantas.

\section{Delineamento experimental e análise estatística}

O experimento foi o delineamento em blocos ao acaso, cinco repetições, sendo as parcelas constituídas de uma fileira com 10 plantas. Para a análise de produção foram avaliados os frutos colhidos de cinco plantas centrais por parcela e para as análises destrutivas (parâmetros da planta e anatomia da foliar) duas plantas por parcela. Todas as análises deste estudo foram realizadas em ambiente R (R CORE TEAM, 2017), versão 3.4.4, utilizando pacote ExpDes.pt. Os dados foram testados para a pressuposição de normalidade dos resíduos (teste de Shapiro-Wilk) e em seguida, os valores médios obtidos foram submetidos ao teste de Tukey, com probabilidade de erro 5\%. Foi realizado teste de correlação de Pearson, aplicando o teste p aos níveis de $5 \%$ de probabilidade de erro, entre as densidades estomáticas das faces abaxial e adaxial, além de produção e número de frutos, por meio do programa estatístico SigmaPlot.

Para a coloração do fruto foi utilizado a Anova e depois a análise dos componentes principais através do programa Genes versão 2019.3. 


\section{Parâmetros da planta e anatomia foliar de tomateiros}

Após 120 dias da semeadura, fez-se a colheita dos tomates e retirada de plantas, no período da manhã. Na coleta foram contados o número de cachos por planta (NC), número de frutos por cacho (NFC) e número de frutos por planta (PF). Foram retiradas as duas últimas plantas de cada parcela (planta com raiz), sendo medidos os seguintes parâmetros por planta: diâmetro do caule foi medido na região do colo (DC); altura da planta (AP) medida em metros, desde o colo até a última folha; área foliar (AF) retirando duas folhas jovens e expandidas, para medição com o equipamento Li-Cor Modelo Li-3100, (Li-Cor Inc., NE, EUA), expressa em centímetros quadrados $\left(\mathrm{cm}^{2}\right)$ por folha ${ }^{-1}$.

As raízes das plantas foram lavadas em água corrente e cortadas em pedaços, acondicionadas juntamente com a planta em sacos de papel tipo kraft, identificados e pesados para obtenção da massa fresca da planta. Após, foi realizada a secagem em estufa de circulação forçada de ar a uma temperatura de $65^{\circ} \mathrm{C}$ durante cinco dias.

Para as análises de anatomia vegetal foram coletadas duas folhas, do terceiro entrenó, de cada planta, sendo fixadas em FAA50 por 48 horas. Após esse tempo, o FAA50 foi substituído por álcool etílico a 70\% (JOHANSEN, 1940). Foram analisados quantitativamente o espessamento dos parênquimas paliçádico e o lacunoso, espessamento do mesofilo, espessura da nervura mediana e do mesofilo foliar com o auxílio do programa Anati Quant $2^{\circledR}$ UFV (AGUIAR et al., 2007).

Para a visualização dos estômatos, foi utilizada a técnica de impressão epidérmica de ambas faces foliares, colando-se amostras da folha em lâmina com adesivo instantâneo universal éster de cianoacrilato (SEGATTO et al., 2004). Após a secagem, retirou-se a folha, fixando somente a impressão das células epidérmicas. Todas as ilustrações foram obtidas por meio do capturador de imagens, acoplado ao fotomicroscópio Leica $\mathrm{DMLB}{ }^{\circledR}$, com o auxílio do programa Leica $\mathrm{IM} 50^{\circledR}$. A densidade estomática foi realizada com o auxílio do programa Anati Quant $2^{\circledR}$ UFV (AGUIAR et al., 2007).

\section{Parâmetros da qualidade dos frutos}

Os frutos colhidos para análise foram retirados do primeiro e segundo cacho, no estádio de maturação vermelho-maduro, estádio 6, livres de doenças e lesões. Foram acondicionados em sacos de polietileno, 4 tomates de cada planta, padronizados por tamanho e cor, representando uma amostra. As amostras foram transportadas em caixas de poliestireno, em temperatura de $7^{\circ} \mathrm{C}$ até o laboratório para análises.

Para as análises de coloração, os frutos foram higienizados e a determinação realizada com o colorímetro portátil CR-400/410 (Konica Minolta ${ }^{\circledR}$ ), expressando os componentes $L^{*}$ [do branco $(+L$ ) ao preto (-L) no eixo $z$ ], a* [do vermelho (+a) ao verde (-a) no eixo $x$ ], b* [do amarelo (+b) ao azul (-b) no eixo y], a saturação de cor croma $(a * 2+b * 2)$ e na tonalidade da cor pelo ângulo de Hue [tan-1 (b*/a*)], conforme López-Camelo et al. (2004). O aparelho foi calibrado no sistema $L^{*} a^{*} b^{*}$ com uma placa branca padrão de cerâmica. 
Para analisar o teor de sólidos solúveis foi utilizado o refratômetro modelo ITREFD 45/65/92, marca Instrutemp ${ }^{\circledast}$ (IAL, 2008), expressando os valores encontrados em ${ }^{\circ}$ Brix. A acidez total titulável foi analisada por titulação com $\mathrm{NaOH}$ 0,1M, sob agitação constante, até coloração rósea, conforme descrito por Pregnolatto et al. (1985), expressa em porcentagem. A determinação do teor de vitamina C foi através de titulometria pela reação com o corante 2,6-dicloroindofenol, expresso em mg de ácido ascórbico/100g de fruto (BRASIL, 1986).

Os teores de Licopeno e $\beta$-caroteno foram determinados utilizando amostras de $1 \mathrm{~g}$ de polpa, homogeneizadas por um minuto com $10 \mathrm{ml}$ de mistura acetona-hexano (4:6) em tubos de ensaio. 0 extrato sobrenadante foi usado para leitura da absorbância em espectrofotômetro Evolution 160 UV - VIS, marca Thermo cientific ${ }^{\circledast}$, em quatro comprimentos de onda: 453, 505, 645 e $663 \mathrm{~nm}$. Os cálculos das concentrações de Licopeno e $\beta$-caroteno foram determinados segundo Nagata et al. (1992). O índice de maturação (IM) 'Ratio': obtido através da relação entre os sólidos solúveis (SS) e a acidez titulável (AT), sendo IM = SS/AT (TRESSLER et al., 1961).

\section{Parâmetros produtivos do tomateiro}

Foram colhidos os frutos maduros duas vezes por semana, no período de 25 de abril a 28 de maio de 2018 avaliando os frutos comerciais (sem defeitos aparentes) e com estes dados foram mensurados a produção t ha ${ }^{-1}$ e número de frutos por planta.

\section{RESULTADOS E DISCUSSÃO}

\section{Parâmetros morfológicos do tomateiro}

Os tomateiros dos híbridos 'Vedette' e 'Fascínio' apresentaram maior altura comparado com ao de 'Mariana' que obteve menor valor para altura (Tabela 1). A altura elevada pode ser um fator indesejável, pois espera-se plantas mais compactas. A altura da planta é uma característica fisiológica de cada híbrido. 0 crescimento da planta, aumenta o auto sombreamento dificultando a expansão da área foliar, mas isso não altera os padrões de ganho de massa seca e área foliar total (ANTÔNIO et al., 2017).

Os resultados apresentados para altura de plantas, comparado com experimento com os híbridos Dominador e Giovanna que são híbridos de hábito indeterminado, em ambiente protegido, com cobertura de $50 \%$ de luminosidade obteve a média de $1,43 \mathrm{~m}$ de altura, sendo relacionado esta característica às altas temperaturas, afirmando, pois, que afeta diversos processos biológicos da planta, em especial o crescimento (OTONI et al., 2012).

As folhas dos híbridos estudados apresentaram área foliar com variação entre 211,56 a 283,45 cm², não havendo diferença estatística entre os materiais testados (Tabela 1). A massa seca das plantas de tomateiro variou de 87,88 a 199,08 g planta $^{-1}$, porém não apresentaram diferença estatística entre os híbridos estudados (Tabela 1).

Quanto ao diâmetro do caule, os híbridos 'Shanty' e 'Mariana' apresentaram maiores valores 4,70 e 
4,60 cm, respectivamente (Tabela 1). Os menores valores para diâmetro do caule foram os híbridos 'Tytanium' com 4,11cm e 'Candieiro' com 4,22cm. Os resultados para diâmetro do caule não apresentaram diferença estatística entre os híbridos estudados.

Tabela 1: Sete híbridos de tomate e sete variáveis morfológicas: Altura da Planta (AP), Área Foliar da folha (AF), Massa Seca da planta (MS), Diâmetro Caule (DC), Número de Cachos por Planta (NC), Número de Frutos por Cacho (NFC) e Número de Frutos por Planta (PF) (Seven tomato híbridos and seven morphological variables: Plant Height (AP), Leaf Foliar Area (AF), Plant Dry Mass (DM), Stem Diameter (DC), Number of Bunches per Plant Number of Fruits per Cluster (NFC) and Number of Fruits per Plant (PF) Alta Floresta (MT).

\begin{tabular}{|c|c|c|c|c|c|c|c|}
\hline Híbrido & $\begin{array}{l}\text { AP } \\
(\mathrm{m})\end{array}$ & $\begin{array}{l}\text { AF } \\
\left(\mathrm{cm}^{2}\right)\end{array}$ & $\begin{array}{l}\text { MS } \\
\text { (g) }\end{array}$ & $\begin{array}{l}\mathrm{DC} \\
(\mathrm{cm})\end{array}$ & NC & NFC & NFP \\
\hline Fascínio & $2,01 a$ & 278,82 & 189,74 & 4,36 & 10,9 & 2,29 & 30,3 \\
\hline Lampião & $1,85 a b$ & 283,45 & 87,88 & 4,44 & 16,7 & 2,35 & 38,4 \\
\hline Vedette & $2,10 a$ & 268,23 & 174,95 & 4,43 & 14,8 & 2,85 & 36,7 \\
\hline Tytanium & $1,92 \mathrm{ab}$ & 211,56 & 112,91 & 4,11 & 12,7 & 2,36 & 31,7 \\
\hline Candieiro & $1,67 a b$ & 233,22 & 128,56 & 4,22 & 13,0 & 2,32 & 28,0 \\
\hline Mariana & $1,27 b$ & 251,47 & 112,88 & 4,60 & 11,3 & 2,32 & 29,3 \\
\hline Shanty & $1,67 a b$ & 279,82 & 199,08 & 4,70 & 15,1 & 2,28 & 36,2 \\
\hline Média & $1,78 * *$ & $278,82^{n s}$ & $143,71^{\mathrm{ns}}$ & $4,40^{\text {ns }}$ & $11,3^{\text {ns }}$ & $2,39^{\text {ns }}$ & $32,90^{\text {ns }}$ \\
\hline CV (\%) & 20,31 & 21,14 & 39,42 & 11,88 & 35,25 & 18,33 & 32,69 \\
\hline
\end{tabular}

Médias seguidas por letras minúsculas na mesma linha, não diferem entre si, pelo teste de Tukey a $5 \%$. Means followed by lower case letters on the same line do not differ from each other, by Tukey test at $5 \%$.

O maior número de cachos por planta (NC) foi observado nos híbridos 'Lampião' $(16,7)$ e 'Shanty' $(15,1)$, enquanto os híbridos 'Fascínio' $(10,9)$ e 'Mariana' $(11,3)$ apresentaram menores quantidades de cachos por planta (Tabela 1). Para o número de frutos por cacho (NFC), os híbridos 'Vedette' $(2,85)$, 'Tytanium' $(2,36)$ e 'Lampião' $(2,35)$ se destacaram, enquanto os híbridos 'Shanty' $(2,28)$ e 'Fascínio' $(2,29)$ apresentaram menores quantidades de frutos por cacho (Tabela 1).

Em relação ao número de frutos por planta (NFP), os híbridos 'Lampião' $(38,4)$ e 'Vedette' $(36,7)$ apresentaram maior valores e os híbridos 'Candieiro' $(28,0)$ e 'Mariana' $(29,3)$ obtiveram menores quantidades (Tabela 1). Os resultados apresentados para o número de cachos por planta (NC), número de frutos por cacho (NFC) e número de frutos por planta não apresentaram diferença significativa estatisticamente entre os híbridos estudados.

\section{Parâmetros anatômicos das folhas de tomateiros}

Para os parâmetros anatômicos entre os híbridos de tomateiro apenas para a densidade estomática adaxial ocorreu diferença entre os mesmos, onde o híbrido 'Fascínio' apresentou a maior densidade mas diferiu somente do híbrido 'Shanty' (Tabela 2).

Considerando que todos os híbridos foram cultivados sob mesmas condições agronômicas e ambientais, provavelmente as diferenças existentes sejam características individual de cada híbrido, pois não houve significância estatística entre as variáveis relacionadas às estruturas morfológicas e produtivas, o que sugere adaptação de todos os híbridos testados nesse ambiente.

A quantidade de estômatos é uma característica específica de cada espécie, podendo ser alteradas em adaptação às condições ambientais, já a densidade estomática depende da idade da folha e área que possui (RODRÍGUEZ et al., 2016). Em berinjela híbrida Ciça, cultivada sob ambiente protegido, apresentou 
aumento na taxa fotossintética com o acréscimo da disponibilidade hídrica no ambiente (SILVA et al., 2005).

A híbrido Fascínio foi o que proporcionou maior densidade estomática na epiderme da face adaxial com 141,12 $\mathrm{mm}^{2}$, que os demais híbridos, apresentaram densidade estomática superior, na epiderme adaxial, com valores entre 65,36 a 78,31 mm². O comportamento estomático observado do híbrido 'Fascínio' é similar àquele ocorrido em plantas expostas a altas intensidades de radiação em relação àquelas expostas à baixa intensidade (MELO et al., 2011).

Tabela 2: Sete híbridos de tomate e cinco variáveis anatômicas foliares: densidade estomática adaxial (DEA), densidade estomática abaxial (DEB), nervura central (NC), parênquima paliçádico (PP), parênquima lacunoso (PL) e mesofilo (MM) (Seven tomato híbridos and five leaf anatomical variables: adaxial stomatal density (DEA), adaxial stomatal density (DEB), central vein (NC), paliçadic parenchyma (PP), lacunar parenchyma (PL) and mesophyll) Alta Floresta (MT).

\begin{tabular}{|c|c|c|c|c|c|c|}
\hline Híbrido & $\begin{array}{l}\text { DEB } \\
\left(\mathrm{mm}^{2}\right)\end{array}$ & $\begin{array}{l}\text { DEA } \\
\left(\mathrm{mm}^{2}\right)\end{array}$ & $\begin{array}{l}\text { NC } \\
(\mu \mathrm{m})\end{array}$ & $\begin{array}{l}\text { PP } \\
(\mu \mathrm{m})\end{array}$ & $\begin{array}{l}\text { PL } \\
(\mu \mathrm{m})\end{array}$ & $\begin{array}{l}\text { MM } \\
(\mu \mathrm{m})\end{array}$ \\
\hline Fascínio & $199,76 a$ & 141,12 & 1490,33 & 131,32 & 124,19 & 255,51 \\
\hline Lampião & $144,78 a b$ & 106,29 & 1383,85 & 153,45 & 149,35 & 302,80 \\
\hline Vedette & $169,52 a b$ & 129,21 & 1664,71 & 146,54 & 150,62 & 297,16 \\
\hline Tytanium & $175,97 a b$ & 151,75 & 1445,15 & 149,11 & 102,82 & 251,93 \\
\hline Candieiro & $148,82 a b$ & 117,29 & 1537,54 & 132,57 & 139,29 & 271,85 \\
\hline Mariana & $162,62 a b$ & 117,04 & 1558,9 & 133,56 & 125,78 & 259,34 \\
\hline Shanty & $116,61 b$ & 110,04 & 1262,45 & 124,75 & 106,14 & 230,88 \\
\hline Média & $158,09 * *$ & $124,68^{\text {ns }}$ & $1477,56^{\text {ns }}$ & $138,75^{\text {ns }}$ & $128,31^{\mathrm{ns}}$ & $267,06^{\text {ns }}$ \\
\hline CV (\%) & 25,64 & 27,19 & 20,14 & 27,12 & 40,7 & 31,58 \\
\hline
\end{tabular}

Means followed by lower case letters on the same line do not differ from each other, by Tukey test at $5 \%$.

O híbrido 'Mariana' expressou a menor densidade estomática na epiderme adaxial (Tabela 2), evidenciando assim, diferenças de respostas estruturais a intensidade da radiação. Comparando a densidade estomática com plantas do cerrado, Elias et al. (2003) enfatizam que na folha de Solanum lycocarpum, apresentaram 538 por $\mathrm{mm}^{2}$ na epiderme adaxial, valor superior a híbrido Fascínio com 141.12 mm². Esta característica da densidade estomática da Solanum lycocarpum evidencia adaptação desta planta no cerrado (ELIAS et al., 2003).

Quanto a densidade estomática, os híbridos 'Fascínio', 'Vedette', 'Lampião', 'Mariana' e 'Shanty' apresentaram maiores concentrações na face abaxial, enquanto os híbridos 'Tytanium' e 'Candieiro', expressaram as menores densidades (Tabela 2). É um evento comum às folhas de sol este aumento na densidade estomática, comparadas às folhas de sombra (MELO et al., 2011). A pesquisa realizada por Rodríguez et al. (2016) com Solanace tuberosum L., apresentaram resultados semelhantes, onde a face abaxial $\left(96,7 \mathrm{~mm}^{2}\right)$ obteve maior densidade estomática se comparado com a face adaxial $\left(23,3 \mathrm{~mm}^{2}\right) \mathrm{com}^{2} 0$ DAT.

O mesofilo dos híbridos é dorsiventral, com parênquima paliçádico formado por uma camada de células longas e estreitas e o parênquima lacunoso voltado para a face abaxial, formado de três a seis camadas de células poliédricas, que mostram espaços entre as células (Fig. A3), com exceção dos híbridos 'Candieiro' e 'Shanty', que apresentaram o parênquima lacunoso com células compactas (Figs. A5 e 7). A híbrido 'Lampião' apresentou maior espessura de mesofilo (302,80 $\mu \mathrm{m}$ ) (Tabela 2). A espessura do mesofilo em plantas é uma característica altamente plástica e tem se mostrado responsiva a diferentes situações ambientais às quais as plantas são submetidas (MELO et al., 2011). 
As espessuras do parênquima paliçádico (PP) encontradas nos híbridos 'Fascínio', 'Lampião', 'Tytanium', 'Mariana' e 'Shanty' foram maiores do que o parênquima lacunoso (PL) em relação aos demais híbridos ('Vedette' e 'Candieiro'), nas quais a relação foi inversa (Tabela 2). Embora observadas essas características anatômicas, não houve significância estatística entre os híbridos.

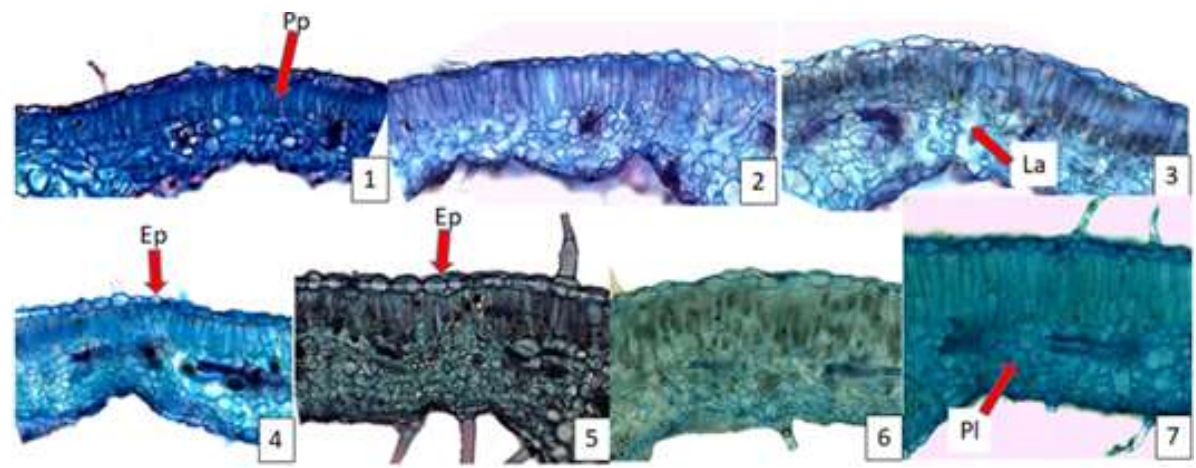

Figura A: Seç̧ões transversais com aspectos gerais do mesofilo foliar de sete híbridos de tomateiro: 'Fascínio' (1), 'Lampião' (2), 'Vedette' (3), 'Tytanium' (4), 'Candieiro' (5), 'Mariana' (6) e 'Shanty' (7). Epiderme (Ep), Lacunas de ar (La), Parênquima paliçádico (Pp), Parênima lacunoso (PI) (Cross sections with general aspects of leaf mesophyll of seven tomato híbridos: 'Fascínio' (1), 'Lampião' (2), 'Vedette' (3), 'Tytanium' (4), 'Candieiro'), 'Mariana' (6) and 'Shanty'

(7). Epidermis (Ep), air gaps (La), palisade parenchyma (Pp), lacunar parenchyma (PI) Alta Floresta (MT).

A espessura do feixe vascular da nervura principal foi maior nos híbridos 'Vedette' (1664,71 $\mu \mathrm{m})$, 'Mariana' (1558,9 $\mu \mathrm{m})$ enquanto o híbrido 'Shanty' apresentou menor valor (1262.45 $\mu \mathrm{m})$ (Tabela 2). As medidas da nervura principal das plantas analisadas, não apresentaram diferença significativa entre os híbridos estudados.

\section{Correlação de Pearson de parâmetros da anatomia foliar e produção de tomateiros}

Foi observado correlação significativa pelo teste de Pearson entre a densidade estomática das faces abaxial e adaxial para os híbridos 'Tytanium', 'Candieiro' e 'Shanty'. Entretanto, não houve correlação significativa entre densidade estomática com produção e no de frutos por planta (Quadro 1). A correlação positiva da densidade estomática entre as faces abaxial e adaxial, que ocorreram somente em três dos híbridos, provavelmente ocorre devido a característica individual de expressão gênica de cada híbrido. A ausência de correlação entre densidade estomática com produção, possivelmente também esteja ligada a expressão de cada híbrido ao ambiente de cultivo protegido, pois nem todos os híbridos que mais produziram, apresentaram maior densidade estomática.

Analisando espécies selvagens de baixa produtividade em comparação com híbridos comerciais de tomateiro, altamente produtivos cultivados em ambiente protegido, Zeist et al. (2018), encontraram grande variação de densidade estomática nas faces abaxial com máximo de 223,33 mm² e adaxial com máxima de $100 \mathrm{~mm}^{2}$, relacionando com a atividade fotossintética de cada híbrido.

A eficiência fotossintética pode estar relacionada com o tamanho e forma dos estômatos, além da densidade estomática, considerando ainda que os estômatos não são as únicas estruturas foliares responsáveis pela fotossíntese. Os estômatos são formados através da divisão celular desde a plântula através da luminosidade e superexpressão gênica, relacionada com a eficiência fotossintética (KLERMUND et 
al., 2016), sendo estruturas importantes para produtividade vegetal, pois são a porta de entrada e escoamento de gases, influenciando diretamente a fotossíntese (SILVA et al., 2005; ZEIST et al., 2018). No entanto, em experimento com cultivo de quatro variedades de batata, Rodríguez et al. (2016) encontraram uma relação diretamente proporcional entre maior densidade estomática e menor tamanho dos estômatos.

Quadro 1: Matrizes de coeficientes de correlação linear de Pearson entre variáveis anatômicas da folha e produtividade de tomate dos híbridos 'Tytanium', 'Candieiro' e 'Shanty', cultivados em ambiente protegido. Produção \{Produção (t ha' 1)\}; Número de frutos por planta (№ fruto/planta); densidade estomática da face abaxial \{Dens. Est. ABA $\left.\left(\mathrm{mm}^{2}\right)\right\} ;$ e densidade estomática da face adaxial \{Dens. Est. ADA $\left.\left(\mathrm{mm}^{2}\right)\right\}$. (Pearson correlation coefficient matrices between leaf anatomical variables and tomato productivity of 'Tytanium', 'Candieiro' and 'Shanty' hybrids grown under protected environment. Production \{Production ( $t$ ha-1)\}; Number of fruits per plant (No. fruit / plant); stomatal density of the adaxial face \{Dens. Est. ABA (mm2)\}; and stomatal density of the adaxial face (Dens. ADA (mm2)\}.Alta Floresta (MT).

\begin{tabular}{|c|c|c|c|c|c|c|c|c|c|}
\hline \multirow[b]{3}{*}{$\begin{array}{l}\text { Produtividade } \\
\left(\mathrm{t} \mathrm{ha}^{-1}\right)\end{array}$} & \multirow{2}{*}{$\begin{array}{l}\text { Tytanium } \\
\text { Fruto } \\
\text { (no } \\
\text { planta-1) }^{-1}\end{array}$} & \multicolumn{2}{|c|}{$\begin{array}{l}\text { Densidade } \\
\text { Estomática }\end{array}$} & \multirow{2}{*}{$\begin{array}{l}\text { Candieiro } \\
\text { Fruto } \\
\text { (no } \\
\text { planta-1) }^{-1} \text { ) }\end{array}$} & \multicolumn{2}{|c|}{$\begin{array}{l}\text { Densidade } \\
\text { Estomática }\end{array}$} & \multirow{2}{*}{$\begin{array}{l}\text { Shanty } \\
\text { Fruto } \\
\text { (no } \\
\text { planta-1) }^{-1}\end{array}$} & \multicolumn{2}{|c|}{$\begin{array}{l}\text { Densidade } \\
\text { Estomática }\end{array}$} \\
\hline & & $\begin{array}{l}\text { ABA } \\
\left(\mathrm{mm}^{2}\right)\end{array}$ & $\begin{array}{l}\text { ADA } \\
\left(\mathrm{mm}^{2}\right) \\
\end{array}$ & & $\begin{array}{l}\text { ABA } \\
\left(\mathrm{mm}^{2}\right)\end{array}$ & $\begin{array}{l}\text { ADA } \\
\left(\mathrm{mm}^{2}\right)\end{array}$ & & $\begin{array}{l}\text { ABA } \\
\left(\mathrm{mm}^{2}\right)\end{array}$ & $\begin{array}{l}\text { ADA } \\
\left(\mathrm{mm}^{2}\right)\end{array}$ \\
\hline & $0,910^{*}$ & $-0,834^{\text {ns }}$ & $-0,860^{\mathrm{ns}}$ & $0,397^{\text {ns }}$ & $0,118^{\text {ns }}$ & $0,476^{\mathrm{ns}}$ & $0,868^{\text {ns }}$ & $0,389^{\text {ns }}$ & $0,494^{n s}$ \\
\hline $\begin{array}{l}\text { Fruto } \\
\left(\mathrm{n}=\text { planta }^{-1}\right)\end{array}$ & & $-0,757^{\mathrm{ns}}$ & $-0,757^{\mathrm{ns}}$ & & $0,825^{\mathrm{ns}}$ & $0,865^{\mathrm{ns}}$ & & $0,255^{\mathrm{ns}}$ & $0,518^{\text {ns }}$ \\
\hline $\begin{array}{l}\text { Densidade } \\
\text { Estomática ABA } \\
\left(\mathrm{mm}^{2}\right)\end{array}$ & & & $0,920^{*}$ & & & $0,903 *$ & & & $0,930 *$ \\
\hline
\end{tabular}

* Significant value at $5 \%$ probability in the $p$-test. ${ }^{* *}$ Significant value at $1 \%$ probability in the $p$ test.

\section{Parâmetros qualitativos dos frutos}

Os três primeiros componentes principais explicam 90,09\% da variação entre os sete híbridos de tomate (Tabela 3) relacionados entre si pela dispersão gráfica apresentada (Figura B). Há separação de três grupos: A) 'Vedette'; B) 'Candieiro'; e C) 'Fascínio'; 'Lampião'; 'Tytanium'; 'Mariana'; e 'Shanty'. Essa discriminação sugere padrões de coloração dos frutos, agrupando os híbridos pela semelhança de aparência.

Tabela 3: Autovalores (Raiz) correspondentes às porcentagens de variação explicadas por Componentes Principais (CPi) de 05 variáveis qualitativas relacionados com espectrofotometria (cor do fruto): L*, a*, b*, Hue (H) e CROMA, avaliadas em 07 acessos de tomate( Eigenvalues (Root) corresponding to percentages of variation explained by Principal Components $(\mathrm{CPi})$ of 05 qualitative variables related to spectrophotometry (fruit color): $\mathrm{L}^{*}, \mathrm{a}^{*}, \mathrm{~b}^{*}, \mathrm{Hue}(\mathrm{H})$ and CROMA, evaluated in 07 accesses of tomato, Alta Floresta (MT), UNEMAT, 2019).

\begin{tabular}{llll}
\hline Autovalores & & & \\
\hline CPi & Raiz & Raiz (\%) & \% Acumulada \\
\hline CP1 & 2.44 & 48.72 & 48.72 \\
CP2 & 1.24 & 24.79 & 73.51 \\
CP3 & 0.83 & 16.57 & 90.09 \\
CP4 & 0.41 & 8.20 & 98.29 \\
CP5 & 0.09 & 1.71 & 100 \\
\hline
\end{tabular}

O híbrido 'Vedette', isolado no grupo A (Figura B), apresentou maior valor para luminosidade $L^{*}$ e maior grau de ângulo Hue, conferindo-Ihe respectivamente maior reflexo luminoso e tonalidade amarelada entre os híbridos testados. A Luminosidade $L^{*}$ pode ser definida como a capacidade de o objeto refletir ou transmitir luz (LÓPEZ-CAMELO et al., 2004), sendo um parâmetro que pode variar do zero (preto) ao 100 (branco) (TRIGO et al., 2012). À medida que os frutos amadurecem, perdem brilho, diminuindo a coloração 
verde e prevalecendo a vermelha, devido à síntese de carotenoides (CARVALHO et al., 2005).

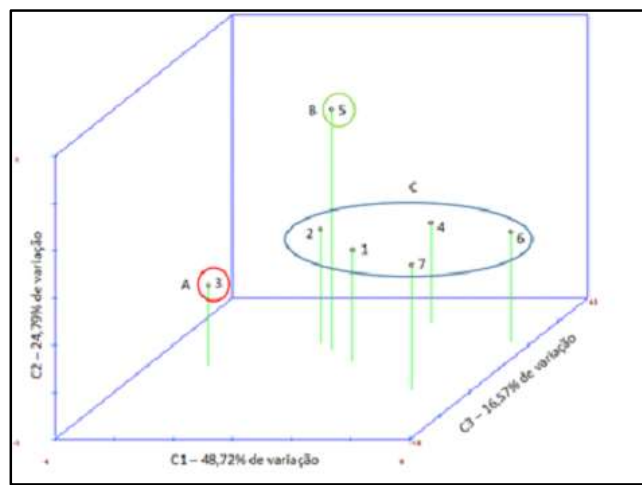

Figura B: Dispersão dos sete híbridos nos três componentes principais (CPi): Grupo A ('Vedette'), Grupo B ('Candieiro') e Grupo C ('Fascínio'; 'Lampião'; 'Tytanium'; 'Mariana'; e 'Shanty') (The dispersion of the seven híbridos in the three main components (CPi): Group A ('Vedette'), Group B ('Candieiro') and Group C ('Fascínio', 'Lampião', 'Tytanium', 'Mariana' and 'Shanty', Alta Floresta (MT).

Os menores valores de Hue representam frutos mais vermelhos, enquanto os maiores, mais amarelos (TRIGO et al., 2012). O processo de amadurecimento de frutos de tomate está ligado à predominância da cor vermelha, resultado da degradação de clorofila e síntese de licopeno, pigmento este que dá a cor característica ao fruto de tomate maduro (LÓPEZ-CAMELO et al., 2004), porém, essa característica vem de fatores genéticos. Paula et al. (2015) estudando vários híbridos diferentes, afirmaram que o genótipo influencia os teores de compostos bioativos, independentemente do estádio de maturação no momento da colheita. Frutos mais vermelhos são mais atraentes ao consumidor (SÁ et al., 2008).

O híbrido 'Candieiro', isolado no grupo B (Figura B) apresentou menores valores para luminosidade $\left(L^{*}\right)$ e componente cromático $\left(b^{*}\right)$, determinando baixa luminosidade e coloração escura, sugerindo maior maturação do fruto. Quando os pigmentos de cor vermelha começam a ser sintetizados, o valor $\mathrm{L}^{*}$ decresce indicando o escurecimento da cor vermelha, i.e., do rosa ao vermelho (LÓPEZ-CAMELO et al., 2004). Onde valores positivos representam frutos que já passaram do ponto verde-maduro, tendendo ao vermelho (CARVALHO et al., 2005). O componente cromático b* menor, representa maior amadurecimento (CARVALHO et al., 2005).

O Grupo C - 'Fascínio'; 'Lampião'; 'Tytanium'; 'Mariana'; e 'Shanty' (Figura B) apresentam uma variação maior entre os componentes relacionados a espectrofotometria, com mais baixos valores para ângulo Hue. Esse resultado indica que os frutos dos 5 híbridos variam entre tons de amarelo, alaranjado e vermelho, demonstrando uma distinção entre os outros dois grupos. A cor do tomate é um indicativo de substâncias denominadas carotenoides, estas substâncias dão a coloração amarela, laranja e vermelha, sendo os tipos mais relatados na composição do tomate, o licopeno e o $\beta$-caroteno (FERNANDES et al. 2018), associado a acentuada síntese de licopeno (CARVALHO et al., 2005; LÓPEZ-CAMELO et al., 2004).

A cor amarela pode estar mascarada pelo $\beta$-caroteno, que favorece a coloração mais alaranjada (CARVALHO et al., 2005; LÓPEZ-CAMELO et al., 2004). Os zeta-carotenos (cor amarelo pálido) atingem sua maior concentração antes do amadurecimento total, onde o licopeno e o $\beta$-caroteno atingem seus picos (LÓPEZ-CAMELO et al., 2004). 
O teor de licopeno (LICOP) no híbrido 'Lampião' foi superior aos demais híbridos avaliados (Tabela 4). Ainda que não tenha se destacado para coloração vermelha, o alto teor de Licopeno possivelmente esteja relacionado à condição genotípica, considerando que todos os híbridos foram cultivados no mesmo ambiente. A concentração de Licopeno no tomate está relacionada ao ponto de maturação, a genética e interação do genótipo com ambiente (PAULA et al., 2015).

Tabela 4: Sete híbridos de tomate e cinco variáveis qualitativas: Licopeno, sólidos solúveis (SS), ácidos totais tituláveis (ATT), vitamina C (VITC) e $\beta$-caroteno C (BETAC) (Seven tomato híbridos and five qualitative variables: Lycopene (LICOP), total soluble solids (TSS), total titratable acids (ATT), vitamin C (VITC) and $\beta$-carotene C (BETAC), Alta Floresta (MT).

\begin{tabular}{|c|c|c|c|c|c|}
\hline Híbridos & $\begin{array}{l}\text { Licopeno } \\
\left(\mathrm{mg} 100 \mathrm{~g}^{-1}\right)\end{array}$ & $\begin{array}{l}\text { SS } \\
\left({ }^{\circ} \text { Brix }\right)\end{array}$ & $\begin{array}{l}\text { ATT } \\
(\%)\end{array}$ & 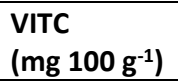 & 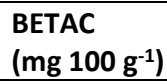 \\
\hline Fascínio & $0,32 \mathrm{~b}$ & $3,48^{\circ} \mathrm{C}$ & 4 & 29,76 & 0,09 \\
\hline Lampião & $0,82 a$ & $4,12^{\circ} \mathrm{a}$ & 4,33 & 34,01 & 0,06 \\
\hline Vedette & $0,40 \mathrm{~b}$ & $3,55^{\circ} \mathrm{C}$ & 4,66 & 28,06 & 0,09 \\
\hline Tytanium & $0,32 b$ & $3,93^{\circ} \mathrm{b}$ & 4,33 & 31,46 & 0,05 \\
\hline Candieiro & $0,48 b$ & $3,83^{\circ} \mathrm{b}$ & 4,33 & 34,01 & 0,06 \\
\hline Mariana & $0,30 \mathrm{~b}$ & $3,90^{\circ} \mathrm{b}$ & 4,1 & 36,56 & 0,05 \\
\hline Shanty & $0,45 b$ & $3,96^{\circ} \mathrm{b}$ & 4,27 & 35,71 & 0,08 \\
\hline Média & $0,448^{* *}$ & $3,82^{*}$ & $4,29 \mathrm{~ns}$ & $32,79 \mathrm{~ns}$ & 0,078ns \\
\hline CV (\%) & 23,94 & 1,33 & 14,84 & 11,11 & 28,22 \\
\hline
\end{tabular}

Médias seguidas por letras minúsculas na mesma linha, não diferem entre si, pelo teste de Tukey a $5 \%$.

Means followed by lower case letters on the same line do not differ from each other, by Tukey test at $5 \%$.

Na concentração de sólidos solúveis totais (SST), o híbrido 'Lampião' apresentou maior concentração, enquanto os híbridos 'Fascínio' e 'Vedette', as menores (Tabela 4). Provavelmente a maior concentração de SST se dá por resposta genética. O sabor dos frutos é determinado pela concentração de SST, podendo ser influenciados pela adubação, temperatura e irrigação, mas principalmente por ser uma característica genética do híbrido (SHIRAHIGE et al., 2010). O maior teor de SST pode melhorar a aceitação do produto para o consumidor, além disso, esta característica também contribui para aptidão do produto para processamento, sendo recomendados valores entre $4^{\circ}$ e $6^{\circ}$ Brix (GIORDANO et al., 2000). O maior conteúdo de açúcares (Brixº ) redutores está correlacionado com a maior doçura do fruto (PAULA et al., 2015).

Os teores de ácidos totais tituláveis (ATT), não diferiram significativamente entre os híbridos avaliados (Tabela 4). Os híbridos testados, do grupo Saladete, provavelmente são muito próximos geneticamente para esse atributo, respondendo de forma semelhante ao ambiente e práticas de cultivo. Os ácidos totais tituláveis representam a quantidade de ácidos orgânicos presentes no fruto e a sua adstringência, sendo os principais responsáveis por influenciar o sabor dos frutos (NASCIMENTO et al., 2013).

Quanto ao valor de vitamina C (VITC), não foram observadas diferenças significativas entre os híbridos avaliados (Tabela 4). Apesar de serem genótipos diferentes, não houve expressão diferida para o teor de vitamina C entre os híbridos sob mesmo modo de cultivo e ambiente. Os valores encontrados neste trabalho, são superiores ao valor mínimo ideal, 23 mg/100 g (FERREIRA et al., 2012). A biossíntese de vitamina C está ligada ao genótipo e pode ser influenciada pelas condições de cultivo (LEE et al., 2000).

Neste trabalho, foram observadas relações SST/ATT baixas, menores que 10, o que confere sabor mais ácido. A relação SST/ATT representa o equilíbrio entre açúcares e ácidos (MENEZES et al., 2017) e, quanto maior, mais suave o sabor do fruto, enquanto menores valores, correspondem a um sabor mais ácido 
(NASCIMENTO et al., 2013). A relação maior de SST/ATT é decorrente do processo de maturação dos frutos, concentração dos açúcares na polpa e redução dos ácidos orgânicos, em função do metabolismo respiratório que os consomem para manter a vida útil, enquanto que a redução desta relação indica o consumo dos açúcares (SS) como substrato energético levando a perda de sabor característico e início de senescência (MENEZES et al., 2017). É considerada boa relação SST/ATT quando os valores estão acima de 10 (FERREIRA et al., 2010). De acordo com Kader et al. (1978) os frutos de alta qualidade contêm mais de 0,32\% de acidez, $3 \%$ de sólidos solúveis e ratio maior que 10 . Portanto, os frutos do estudo não se mantiveram dentro destes padrões.

\section{Parâmetros produtivos do tomateiro}

O híbrido 'Lampião' apresentou maior número de frutos em relação aos demais híbridos. Já os híbridos 'Lampião', 'Fascínio' e 'Shanty' apresentaram maior produtividade (Figura D). Os híbridos com as melhores respostas demonstram melhor interação genótipo ambiente. O resultado obtido pelo híbrido Lampião se destaca no presente estudo, sendo 10,85\% maior que os verificados por Kumari et al. (2016) que obtiveram 65,2 t ha' para este mesmo híbrido ao estudarem o cultivo de tomateiro em ambiente protegido. Já o resultado do híbrido "Mariana" foi menor 12,28\% que o apresentado por Schwarz et al. (2015), que em ambiente protegido alcançaram produtividade de tomate 55,01 t ha'. Em experimento utilizando híbridos de tomateiro em ambiente protegido, Otoni et al. (2012) apresentaram produtividade máxima de 35,96 t ha', sendo este resultado bem abaixo do obtido neste presente trabalho. Estes resultados demonstram a influência das condições ambientais sobre a produtividade dos diferentes materiais genéticos.

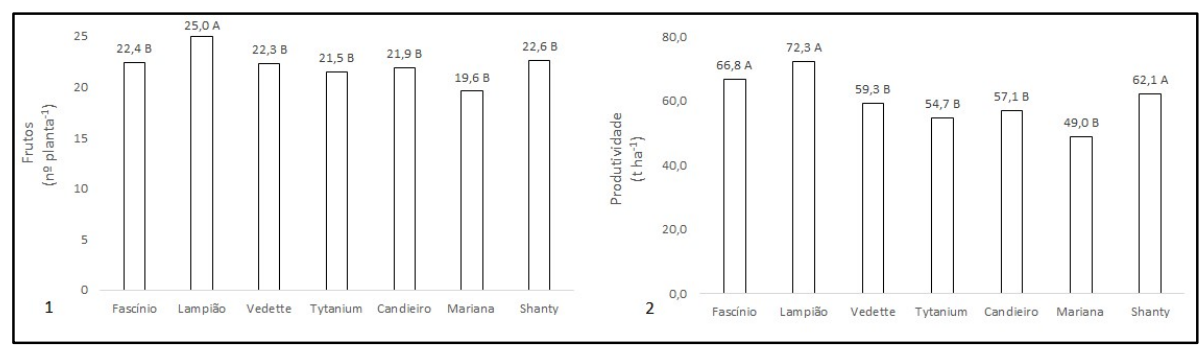

Figura D. Número de frutos por planta (1) e Produtividade (2) de sete híbridos de tomateiro: 'Fascínio', 'Lampião', 'Vedette', 'Tytanium', 'Candieiro', 'Mariana' e 'Shanty' cultivados sob ambiente protegido. Coeficiente de variação: 8,3 $\%$ (1) e 11,3 \% (2). (Number of fruits per plant (1) and Productivity (2) of seven tomato híbridos: 'Fascínio', 'Lampião',

'Vedette', 'Tytanium', 'Candieiro', 'Mariana' and 'Shanty' cultivated under protected environment Coefficient of variation: $8.3 \%(1)$ and $11.3 \%(2)$, Alta Floresta (MT).

\section{CONCLUSÕES}

Os híbridos 'Lampião' 'Fascínio', 'Vedette' e 'Shanty' se destacaram em produção e qualidade nutricional, comparado aos demais. Os parâmetros da anatomia foliar analisados demonstraram alterações adaptativas à luminosidade difusa, umidade e temperatura, não demonstrando correlação com a produção dos híbridos avaliados.

Quanto a coloração do fruto, a híbrido 'Candieiro' apresentou a coloração mais vermelha, mais apreciada comercialmente, enquanto que 'Vedette', coloração mais amarelada. 
O híbrido 'Mariana' mostrou menor desempenho em produtividade, altura da planta e concentração de licopeno, demonstrando menor adaptação ao ambiente protegido sob alta temperaturas.

\section{REFERÊNCIAS}

AGUIAR, T. V.; SANT'ANNA-SANTOS, B. F.; AZEVEDO, A. A.; FERREIRA, R. S.. Anati quanti: software de análises quantitativas para estudos em anatomia vegetal. Planta Daninha, v.25, n.4, p.649-659, 2007. DOI: https://doi.org/10.1590/S0100-83582007000400001

ANTÔNIO, A. C.; SILVA, D. J. K.; ARAÚJO, W. L.; CECON, P. R.. Análise de crescimento de tomate em três sistemas de cultivo Influência do sistema de cultivo no crescimento de plantas de tomate. Horticultura Brasileira, v.35, n.3, p.358363, 2007. DOI: http://dx.doi.org/10.1590/s0102$\underline{053620170307}$

ARAGÃO, D. S.; LUNZ, A. M. O.; OLIVEIRA, L. C.; RAPOSO, A.; FERMINO JUNIOR, R. C. P.. Efeito do sombreamento na anatomia foliar de plantas jovens de andiroba (Carapa guianensis Aubl). Revista Árvore, v.38, n.4, p.631-639, 2014. DOI:

https://doi.org/10.1590/S0100-67622014000400006

BRASIL. Ministério da Agricultura. Portaria n. $\mathbf{7 6}$ de $\mathbf{2 6}$ de novembro de 1986. Dispõe sobre os métodos analíticos de bebidas e vinagre. Brasília: DOU, 1986.

CARVALHO, W.; FONSECA, M. E. N.; SILVA, H. R.; BOITEUX, L. S.; GIODANO, L. B.. Indirect estimation of lycopene concentration in fruits of tomato genotypes via chromaticity values. Horticultura Brasileira, v.23, n.3, p.819-825, 2005. DOI: http://dx.doi.org/10.1590/S0102-053620050 00300026

ELIAS, S. R. M.; ASSIS, R. M.; STACCIARINI-SERAPHIN, E.; REZENDE, M. H.. Leaf anatomy in young plants of Solanum lycocarpum A.St.-Hil. (Solanaceae). Revista Brasileira de Botânica, v.26, n.2, p.169-174, 2003. DOI: https://doi.org/10.1590/S0100-84042003000200004

FERNANDES, M. O.; BIANCHI, P. A.; SILVA, L. R. A.; VIANNA, L. S.; SANTOS, E. A.; MOULIN, M. M.. Caracterização morfoagronômica e análise da diversidade genética entre acessos de tomates (Solanum lycopersicum L.). Ciência Rural, v.48, n.11, p.1-9, 2018. DOI: http://dx.doi. org/ 10.1590/0103$\underline{8478 \mathrm{cr} 20180433}$

FERREIRA, R. M. A.; LOPES, W. A. R.; AROUCHA, E. M. M.; MAN, N. C. S.; SOUSA, C. M. G.. Caracterização física e química de híbridos de tomate em diferentes estádios de maturação produzidos em Baraúna. Revista Ceres, v.59, n.4, p.506-511, 2012. DOI: http://dx.doi.org/10.1590/S0034$\underline{737 \times 2012000400011}$

FERREIRA, S. M. R.; QUADROS, D. A.; KARKLE, E. N. L.; LIMA, J. J.; TULLIO, L. T.; FREITAS, R. J. S.. Qualidade pós-colheita do tomate de mesa convencional e orgânico. Ciência e Tecnologia de Alimento, v.30, n.4, p.858-869, 2010. DOI: http://dx.doi.org/10.1590/S0101-20612010000400004

GIORDANO, L. D. B.; SILVA, J. D.; BARBOSA, V.. Escolha de híbridos e plantio. Tomate para processamento industrial. EMBRAPA, 2000.
IBGE. Instituto Brasileiro de Geografia e Estatística. Estatística mensal da Produção Agrícola Levantamento Sistemático da Produção Agrícola. Rio de Janeiro: IBGE, 2018.

JOHANSEN, D. A.. Plant microtechnique. New York: McGraw-Hill Book Co. Inc., 1940.

KADER, A. A.; MORRIS, L. L.; STEVENS, M. A.; ALBRIGHTHOLTON, M.. Composition and flavor quality of fresh market tomatoes as influenced by some postharvest handling procedures. Journal of the American Society for Horticultural Science, v.103, n.1, p.6-13, 1978.

KLERMUND, C.; RANFTLAN, Q. L.; DIENER, J.; BASTAKIS, E.; RITCHTER, R.; SCHWECHHEIMER, C.. Os fatores de transcrição B-GATA de domínio LLM promovem o desenvolvimento estomático a jusante de vias de sinalização de luz em Hypocotyls de Arabidopsis thaliana hypocotyls. The Plant Cell, v.28, n.3, p.646-660, 2016.

KUMARI, P.; OJHA, R. K.; JOB, M.. Effect of plastic mulches on soil temperature and tomato yield inside and outside the polyhouse. Agricultural Science Digest, v.36, n.4, p.333-336, 2016. DOI: https://doi.org/10.18805/asd.v36i4.6479

LEE, J.; KOO, N.; MIN, D. B.. Reactive oxygen species, aging and antioxidative nutraceuticals. Comprehensive Reviews in Food Science and Food Safety, v.3, n.1, p.21-33, 2000. DOI: https://doi.org/10.1111/j.1541-4337.2004.tb00058.x

LÓPEZ-CAMELO, A. F.; GÓMEZ, P. A.. Comparison of color indexes for tomato ripening. Horticultura Brasileira, v.22, n.3, p.534-537, 2004. DOI: http://dx.doi.org/10.1590/S0102$\underline{05362004000300006}$

PREGNOLATTO, W.; PREGNOLATTO, N. P.. Normas analíticas do Instituto Adolfo Lutz. Métodos químicos e físicos para análise de alimentos. São Paulo: Instituto Adolf Lutz, 1985.

MELO, H. C.; CASTRO, E. M.; ALVES, E.; PERINA, F. J.. Anatomia foliar de microtomateiros fitocromo-mutantes e ultra-estrutura de cloroplastos. Ciências Agrotécnicas, v.35, n.1, p.11-18. 2011. DOI: http://dx.doi.org/10.1590/S1413$\underline{70542011000100001}$

MENEZES, K. R. P.; SANTOS, G. C. S.; OLIVEIRA, O. M.; SANCHES, A. G.; CORDEIRO, M.; OLIVEIRA, A. R. G. A. Influência dos revestimentos comestíveis na preservação da qualidade pós colheita de tomate de mesa. Cólloquium Agrariae, v.13, n.3, p.14-28, 2017. DOI: https://doi.org/10.5747/ca.2017.v13.n3.a170

NAGATA, M.; YAMASHITA, I.. Simple method for simultaneous determination of chlorophyll and carotenoids in tomato fruit. Nippon Shokuhin Kogyo Gakkaishi, v.39, n.10, p.925-928, 1992.

OTONI, B. S.; MOTA, W. F.; BELFORT, G. R.; SILVA, A. R. S; VIEIRA, J. C. B.; ROCHA, L. S.. Produção de híbridos de 
tomateiro cultivados sob diferentes porcentagens de sombreamento. Revista Ceres, v.59, n.6, p.816-825, 2012. DOI: https://doi.org/10.1590/S0034-737X2012000600012

PAULA, J. T.; RESENDE, J. T. V.; FARIA, M. V.; FIGUEIREDO, A. S. T.; SCHWARZ, K.; NEUMANN, E. R.. Physicochemical characteristics and bioactive compounds in tomato fruits harvested at different ripening stages. Horticultura Brasileira, v.33, n.4, p.434-440, 2015. DOI: http://dx. doi. org/10. 15 90/S0102-053620150000400005

R CORE TEAM. R Foundation for Statistical Computing, R: a language and environment for statistical computing. Vienna: R CORE TEAM, 2017.

RAMPAZZO, R.; SEABRA JUNIOR, S.; NUNES, M. C. M.; NEVES, S. M. A. S.; FERREIRA, R. F.. Eficiência de telas termorefletoras e de sombreamento em ambiente Protegido tipo telado sob temperaturas elevadas. Engenharia na agricultura, v.22, n.1, p.33-42, 2014. DOI: https://doi.org /10.13083/1414-3984.V22N01A04

RODRÍGUEZ, A. M.; MENDOZA, Z. V. G.; TEJÓN, A. M.; DEL EL SOL, D. R.; MORALES, S. R.. Caracterización estomática de cuatro variedades de papa (Solanum tuberosum L.). Revista Agricultura Tropical, v.2, n.1, p.9-17, 2016.

SÁ, C. R. L.; SILVA, E. O.; TERAO, D.; OSTER, A. H.. Efeito do KMnO4 e 1-MCP com atmosfera modificada na conservação pós-colheita de melão Cantaloupe. Revista de Ciência Agronômica, v.39, n.1, p.60-69, 2008.
SCHWARZ, K.; RESENDE, J. T. V.; PRECZENHAC, A. P.; PAULA, J. T.; FARIA, M. V.; DIAS, D. M.. Desempenho agronômico e qualidade físico-química de híbridos de tomateiro em cultivo rasteiro. Horticultura Brasileira, v.31, n.3, p.410-418, 2015. DOI: https://doi.org/10.1590/S0102-05362013000300011

SEGATTO, F. B.; BISOGNIN, D. A.; BENEDETTI, M.; COSTA, L. C.; RAMPELOTTO, M. C.. Técnica para estudo da anatomia da epiderme foliar de batata. Ciência Rural, v.34, n.5, p.15971601, 2004.

SILVA, L. M.; ALQUINI, Y.; CAVALLET, V. J.. Inter-relações entre a anatomia vegetal e a produção vegetal. Acta Botânica Brasilica, v.19, n.1, p.183-194. 2005. DOI: https://doi.org/10.1590/S0102-33062005000100018

TRESSLER, D. K.; JOSLYN, M. A.. Fruits and vegetables juice processing technology. Westport: AVI, 1961.

TRIGO, J. M.; ALBERTINI, A. S.; SPOTO, M. F. H.; SARMENTO, S. B. S.; REYES, A. E. L.; SARRIÉS, G. A.. Effect of edible coatings on the preservation of fresh cut papayas. Brazilian Journal Food Technology, v.15, n.2, p.125-133, 2012. DOI: http://dx.doi.org/10.1590/S1981-67232012005000005

ZEIST, A. R.; RESENDE, J. T. V.; FARIA, M. V.; GABRIEL, A.; ADRIANO, E.; LIMA FILHO, R. B.. Photosynthetic characteristics in species and interspecific hybrids of tomato. Horticultura Brasileira, v.36, n.3, p.362-370, 2018. DOI: http://dx.doi.org/10.1590/s0102-05362018031

A CBPC - Companhia Brasileira de Produção Científica (CNPJ: 11.221.422/0001-03) detém os direitos materiais desta publicação. Os direitos referem-se à publicação do trabalho em qualquer parte do mundo, incluindo os direitos às renovaç̃ões, expansões e disseminações da contribuiç̃o, bem como outros direitos subsidiários. Todos os trabalhos publicados eletronicamente poderão posteriormente ser publicados em coletâneas impressas sob coordenação da Sustenere Publishing, da Companhia Brasileira de Produção Científica e seus parceiros autorizados. Os (as) autores (as) preservam os direitos autorais, mas não têm permissão para a publicação da contribuição em outro meio, impresso ou digital, em português ou em tradução. 